\title{
Discussion on Regulation of Illegal Evidence Exclusion
}

\author{
Yuting Gan \\ North China Electric Power University (Baoding), Baoding 071003, China \\ 1106805377@qq.com
}

Keywords: Illegal evidence; legislation plan; exclusionary rule.

\begin{abstract}
This paper introduces the problem of illegal evidence exclusion rules, and pointed out its deficiencies, and exclusive rules of illegal evidence causes various difficulties in their implementation and, finally, from the actual situation in China, improve the legislation plan of the exclusionary rule.
\end{abstract}

\section{Introduction}

Usually refers to the exclusionary rule for illegally obtained evidence in criminal proceedings, investigative organs and their staff in the use of evidence obtained by illegal means shall not be accepted rule in criminal trials. The exclusionary rule of unlawfully obtained confessions and illegal search and seizure of evidence obtained be excluded, shall not be used as evidence collectively. Illegally obtained evidence is a focus of discussion and research, there are many problems in the legislation and practice. In practice there are problems, such as Chen Guangzhong, of scholars agree that regulation of illegal evidence in the research has been our focus.

\subsection{Problems of illegal evidence}

\subsubsection{Torture, threat, inducement is prevalent}

Torture has been repeated during the trial issue, popular ever since. While the current article 54 of the Criminal Procedure law of China stipulates that illegal methods such as torture of criminal suspects and defendants statements, threats of violence and other illegal methods to collect the testimony of a witness, victim statements, shall be excluded. But from the case of she xianglin's murder to Zhao Zuohai, the NIE Shubin injustice we can see torture, threats and inducements and other illegal means still exist in the course of proceedings.

\subsubsection{Law does not specify whether derivative evidence has proven ability}

United States legislation provides for the "fruit of the poisonous tree" theory, for the fruit of the poisonous tree and the tree produces, legislative provisions should be excluded from the United States, British legislation also provides for this theory, however, and the United States have some differences: United Kingdom "ruled out the poisonous tree", "edible fruit of the poisonous tree" principle. However in contrast and is not a "fruit of the poisonous tree" theory, in the provisions of the code of Criminal Procedure only for clues of illegal evidence in our country as "illegal evidence in the original"-Word exclusive rule of illegal evidence, physical evidence of reasonable interpretation and correction is not ruled out. This led to public security organs in the process of illegal collection of evidence would deliberately avoid "oral evidence". Police in gathering evidence in the course of using illegal methods to collect physical evidence may be subject to certain sanctions, but he collected evidence through illegal means will be more rewarding than rewards, punishment will seem so trivial. This is also an important cause of confession by torture despite repeated prohibitions.

\section{2 The existence of illegal evidence}

\subsubsection{The lack of exclusive rules of illegal evidence and its not clear}

Present article 54 of the code of Criminal Procedure stipulates that illegal methods such as torture of criminal suspects and defendants statements, threats of violence and other illegal methods to collect the testimony of a witness, victim statements, shall be excluded. The Act generally requires the investigative organs not illegal exercise of authority through illegal means to obtain the evidence, but for illegal evidence in trials, as well as how much the probative force of the evidence, what evidence 
means of procedures illegal, illegal evidence in criminal law such as the supervisory authorities who are not clearly defined. Subject to disciplinary measures for illegally obtaining evidence there was no clear legislative provisions. 2012 revision of the Criminal Procedure code provides for illegally obtained evidence, if only generally violate the legitimate rights and interests of others, and no violations of the legitimate rights and interests of others, the people's procuratorate finds its effectiveness can be used as evidence. But the provision to some extent contrary to judicial independence (independence) principle, because for evidence of power belonged to the judge, prosecutors involved in certification, a clear breach of the principle of judicial independence. Secondly, our derivative evidence commonly known as "fruit of the poisonous tree" and there is no legislative provision, but courts are not excluded from the practice. In practice will inevitably be illegal evidence are not clearly defined.

\subsubsection{The lack of effective monitoring mechanisms}

XI Jinping, Secretary General said: "shut up in a cage system power", an important reason for the existence of illegal evidence is the lack of effective monitoring mechanisms. Monitoring mechanisms can effectively stop illegal evidence in part on evidence, evidence is so rampant in China, monitoring mechanism is also an important factor. 83rd of the new code of Criminal Procedure provides that public security organs when detaining a person, must produce a detention warrant. After the detention, it shall immediately send the detainees detention in custody may not exceed 24 hours at the latest. In addition cannot be notified or suspected of endangering national security crimes, terrorism alerts might hamper the investigation of cases should be within 24 hours after the detention, informed the families of the detainees. Impede the investigation of disappeared, it shall immediately inform the families of the detainees. 84th provides that public security organs of detained persons shall be within 24 hours after the detention for questioning. When I found should not have been detained, he must be immediately released and issued a release certificate. The provision is mainly prevention and lack of supervision in detention institutions, police torture and other means will be taken. The new code of Criminal Procedure also can't solve the problem of lack of oversight mechanisms.

\subsection{Improving the regulation of illegal evidence in our country}

\subsection{1 legislation}

Shen Xiaoying scholars think through amendment criminal method, will statutory ban forensics of way and ban illegal collection evidence type of range by currently only limited to "to torture confessions or threat, and lure, and cheat, illegal of method collection of crime suspects for said, and victims statement, and witnesses testimony, words evidence", expanded to including "through illegal identified, and illegal custody, and illegal deprived defended right, illegal method collection of words evidence" and "through illegal search, and illegal seized, and illegal invaded citizens residential, and illegal identified, and Illegal detention and illegal surveillance communication, illegal entrapment and other physical evidence acquired by illegal means ", derivative evidence obtained indirectly through such illegal means (the" fruit of the poisonous tree "), including testimonial evidence and physical evidence, were included in the list of illegally obtained evidence can be excluded from [1]. I believe that article 54 of the Criminal Procedure law of China stipulates that illegal methods such as torture of criminal suspects and defendants, and acts of violence, intimidation and other illegal methods to collect the testimony of a witness, victim statements, shall be excluded. Collecting material evidence and documentary evidence legal procedures may influence the course of Justice, shall make corrections or give a reasonable explanation; cannot be corrected or give a reasonable explanation, the evidence should be excluded. Hin scholars think for used "torture confessions, illegal method" of "forced" means, should by courts according to illegal evidence excluded rules in the of statutory excluded processing; for used "threat, and lure, and cheat" of "forced" means, should by judge according to illegal evidence excluded rules of program discretionary excluded; for take "illegal means" indirect gets words evidence, and real evidence of "forced" means, should by judge according to General evidence review program for finds, decided choice [2]. So I think the criminal should have a clear legislative criteria in the criminal law area, I mentioned should be deleted first prosecution for other illegal means to obtain evidence in violation of others ' rights and interests and when there are no 
violations of the legitimate rights and interests of others, when prosecutors found that their effectiveness, the provisions can be used as evidence. Then the criminal derivative evidence should be made to provisions of the law, I think we can refer to the United States, "fruit of the poisonous tree" theory, the British did not rule out the "fruit of the poisonous tree", a "tree fruit" approach, the United States is excluded, "fruit of the poisonous tree", "cut down fruit trees" to eliminate "illegal evidence" typical country [3].This should also be provided for in the Criminal Procedure law in our country, "fruit of the poisonous tree" theory, I believe that the "fruit of the poisonous tree" for verbal and physical evidence available should be absolutely excluded, but also provides some exceptions, such as the "independent sources" and "diluted" exception. Independent sources that Government information is acquired from another independent source, rather than relying on illegally obtained evidence for clues to the get.This does not apply the exclusionary rule. Must find this exception means that this evidence does not depend on illegal evidence "poisonous tree" and can also be obtained through other channels on the evidence. However, the defendant "fruit of the poisonous tree" question, forensics personnel must prove that the evidence was obtained by other clues. There is one exception to this is pollution interrupted, that is, if out of free will of the accused's activities have cut off the illegal links with the evidence obtained subsequently, pollution-break occurs, the proceeds with the admissibility of evidence. Code of Criminal Procedure should be expressly stipulated in legislation, legislation to avoid detrimental practice problems to resolve.

\subsubsection{Establishment of illegal evidence exclusion rules monitoring mechanism}

First of all, judges in the court case, evidence provided by criminal investigation, if it is found that certain evidence is not from a legitimate source, on the weight of the evidence is entitled to make a decision. To pass the legislation, determine the appropriate terms of reference of the judges in the law, and judge the evidence to clearly define the scope of validity of [4]. Second, to strengthen court oversight of the program, fair and objective procedures is an important condition for ensuring the result of the case just. Judges encountered evidence in the trial judgment in accordance with the statutory procedures, within the scope of the statutory authority to make decision, according to the actual situation objectively judged, judge according to detailed records on the case file, easy to verify. Prosecution delay, passive and ineffective, difficult to rectify illegal investigation and supervision issues, I think you can start from the system, establishment of illegal evidence investigation mechanism.

\subsubsection{Broaden the sources of surveillance information}

Clues of illegal evidence found that difficult question, we must strengthen the procuratorial powers of investigation supervision Department access to investigation files and evidence, in principle, as long as no investigation against independence, investigative organs must be matched.These files can be not limited to the investigating authorities to transfer to arrest and prosecution materials, other materials can be involved with this case. For litigation and complaints and appeals made by procuratorial supervision departments should pay high attention to and into the review process in a timely manner, cannot evade or delay [5].

\subsubsection{Investigating cases under investigation in whether to use illegally obtained evidence to assist}

According to the modern law of evidence, burden of proof in cases under investigation for investigation of illegal use is the "onus" rule, procuratorial organs in the performance of illegal collection of evidence, burden of proof, investigating authorities should actively assist in the prosecution of proof he did not use torture, threat, inducement, violence and other illegal means to gather evidence, If proof cannot, it is presumed means of investigation used illegal evidence, will bear administrative liability or criminal liability.

\section{Conclusion}

Exclusive rules of illegal evidence in our country occupies an important position in the field of evidence law, to fundamentally stamp out injustice and construction of "rule of law", the exclusionary 
rule of illegally building and improving essential, should be combined with China's national conditions, legislation and supervision system of perfect exclusion rule of illegal evidence.In the neighborhood built on Criminal Procedure "fruit of the poisonous tree" theory, in the civil procedure law of "illegal" legal forms to be defined, to the parties and judges a clear standard.

\section{References}

[1] ShenXiao ying. Construction of exclusive rules of illegal evidence in China [j]. Journal of Jiangsu police officer College, 2006 (3):

[2] Zhou Xin. public security organs ' exclusive rules of illegal evidence and sound [j]. Journal of Chinese people's public security University (Social Science Edition), 2014 (3): 136.

[3] Song Shiyue YuZe di. Dilemma and outlet of exclusive rules of illegal evidence in China [j]. Journal of Zhanjiang normal College, 2011 (10): 5.

[4] GuoZhiyuan Chen Guangzhong. Research on some problems of implementation of illegal evidence exclusion rules [j]. Law magazine, 2014 (9): 14.

[5] Liang JinRui Ma XiaoHui. Analysis on the causes and prevention of illegal evidence [j]. Gansu Journal of police vocational college, 2009 (4): 16. 